\title{
Computer Aided Design of Circular Reinforced Concrete Silos
}

\author{
Eng. G.A.P. Gampathi, Eng. P.P.P. Peiris
}

Abstract: It is reported each year that a large number of silos, bins and hoppers fail due to bad design, poor construction or improper use. Many failures are the results of loading conditions not correctly accounted for and applied by the designer. This paper describes design procedures that have been found to be successful with computer aided design. In particular, the paper covers the design of a main silo and interstice walls for three loading cases.

\section{Introduction}

Silos are commonly used structure to store raw material in industrial factories. In Sri Lanka, these silos are generally used to store grains to produce food items such as flour and raw material for cement productions. It is reported around the world in recent years, hundred of industrial and farm silos, bins and hoppers fail due to design errors (Safarian \& Harris, 1985). Sometimes their failures are structural collapse or cracks that are found in concrete walls. These data indicate that corrective measures are probably required. Silo design requires specialized knowledge. The designer must first establish the materials flow properties, and then consider such items as flow channel geometry, flow and static pressure development, and dynamic effects. Problems like vibration has to be prevented, while assuming reliable discharge at the required rate, non- uniform loads, thermal loading, and the effect of non-standard fabrication details should be considered. Having established the design criteria, a competent design has to follow.

\section{Objective}

The objective of this study is to determine the effectiveness of the finite element application in silo design, determination of proper way to model silo in finite elements and also to compare these results with manual calculations.

\section{Methodology}

\section{$3.1 \quad$ Loading}

For this study, 50 numbers of silos having diameter of $8 \mathrm{~m}$ and $50 \mathrm{~m}$ height and filled with wheat grains was considered. Properties of the filled material were taken as the following; density $8.5 \mathrm{kN} / \mathrm{m} 3$, friction angle 250 and friction against concrete wall $\mu^{\prime}=0.44$. For load calculation, bulk material properties like friction and cohesion, particle sizes, moisture and temperature condition were taken into account. Flow pattern during discharge also been considered.

In addition to the vertical dead and imposed load, lateral wind load also incorporated to the design.

The following load cases were applied for the design;

- $\quad$ All silos are fully loaded but interstices (additional storage spaces, create by main silos) are empty

- Only interstices are loaded

- All silos and interstices are loaded

Eng. G A P Gampathi- M.Eng (NUS), B.Sc (Hons), AMIE (Sri Lanka), Senior Enginter Sanken Lankn Pot. Ltd

Eng. P P P Peiris - PG Dip (Mornturun), B.Sc (Hons), C.Eng. MIE (Sri Lanka), Mannger Design Sanken Lanki [vul. Ltd. 


\subsection{Theoretical approach}

There are many theories available for design of silos. Even though these theories are accurate enough to evaluate the loading on silos, there are certain problem with the application of these loads on the actual structure. In this design the Reimbert's method has been selected for the computation of static pressure due to stored material. According to the silo theories presented by Raju (1996), the height of the cone on the top surface of the stored material $\left(h_{5}\right)$ for circular silo with diameter $\mathrm{D}$, height $\mathrm{H}$ and store material friction $ø$ is given by:

$h_{\mathrm{S}} \quad=\mathrm{D} / 2 \tan \varnothing$

Friction coefficient (k), maximum pressure $\left(\mathrm{P}_{\max }\right)$ and pressure coefficient $(\mathrm{C})$ with material density $\gamma$ is given by the following equations;

$$
\begin{aligned}
\mathrm{k} & =\frac{1-\operatorname{Sin} \varnothing}{1+\operatorname{Sin} \varnothing} \\
P_{\mathrm{MAX}} & =\frac{Y D}{4 \mu^{\prime}} \\
\mathrm{C} & =\frac{D}{4 \mu^{\prime} \mathrm{k}}-\frac{h_{\mathrm{S}}}{3}
\end{aligned}
$$

With above Reimbert's equations for static pressure $\left(P_{s t}\right)$ at depth $Y$ from the top of the surface can be calculated by following equation:

$$
P_{\mathrm{ST}} \quad=P_{\mathrm{MAX}}\left[1-\left(\frac{Y}{\mathrm{C}}+1\right)^{-2}\right]
$$

Then design pressure

$$
P_{d e s}=C_{d} P_{s t}
$$

Where $C_{d}$ is the overpressure factor

Hoop tension

$$
F_{u} \quad=1.7-\frac{D}{2} P_{\text {des }}
$$

Required steel

$$
\text { As } \quad=\frac{F_{u}}{ø f_{y}}
$$

Where $\varnothing=0.9$ for tension and $f_{y}=$ yield strength of steel
Vertical pressure given by following equations

$$
q_{\mathrm{sT}} \quad=\gamma\left[Y\left(\frac{Y}{C}+1\right)^{-1}+\frac{h_{\mathrm{s}}}{3}\right]
$$

Force on main silo walls can be determined by using the above equations. With the same procedure and considering equilibrium of forces on interstice wall, hoop tension/compression, shear forces and bending moment, on interstice walls can be calculated.

However, in addition to the required reinforcement calculation to tally with the above forces and moments, thermal steel requirement also need to be added to get the total steel requirement, further the available code requirement for the minimum reinforcement should also be satisfied, according to the standard code requirement; maximum contribution from concrete wall itself to resist vertical load is $0.35 \mathrm{f} b \mathrm{~b}$, where $\mathrm{b}=1000 \mathrm{~mm}$ and $\mathrm{h}$ is the wall thickness, minimum vertical reinforcement requirement is $0.0020 \mathrm{Ac}$ where $\mathrm{Ac}$ is the concrete area, minimum hoop steel requirement is $0.0025 \mathrm{Ac}$. Further, crack width calculation should also be carried out and it should also be within the acceptable limit.

\subsection{Numerical Approach \\ 3.3.1 Model:}

The total analysis was done based on a finite element model in SAP2000. Lateral stability was measured in terms of fundamental period of vibration and deflection for wind loads. The wind load analysis was done based on loads evaluated from CP3: Chapter V as it is widely used in Sri Lanka.

For the analysis, an actual structure intended for Prima Ceylon was considered. The structure consisted of piled raft foundation; having depth of $1.4 \mathrm{~m}$ and 50 number of Silos; having diameter of $8 \mathrm{~m}$ and $50 \mathrm{~m}$ in height. There were two service stories on top of the silo structure.

\subsubsection{Method of Modeling:}

When designing a structure using finite element technique, first of all, a suitable finite element must be selected to represent the behavior of the structure. In modeling, either solid elements or shell elements can be selected for silo walls and piled raft. However having solid elements are very complicate. Therefore, shell elements were 
selected for modeling this problem. Further it is important to study the shearing deformations when the thickness of the shell element is greater than about one-tenth to one-fifth of the span.

When there are sudden changes in thickness, there can be significant bending stress concentration; for example at hopper or support conditions, and near holes or re- entrant corners. In this model shearing deformations have been taken into account as follows;

When defining the shell element properties, select thick plate option for pile raft and hopper slab and select thin plate option for the silo walls. Thin plate option neglects transverse shearing deformation, but thick plate formulation includes the effects of transverse shearing deformation.

Creating a model of silo is straightforward with an advance finite element package such as SAP2000. However, there are certain aspects that the designer must be aware of in this situation. All shell elements must be properly connected to adjoining elements to have proper connectivity.

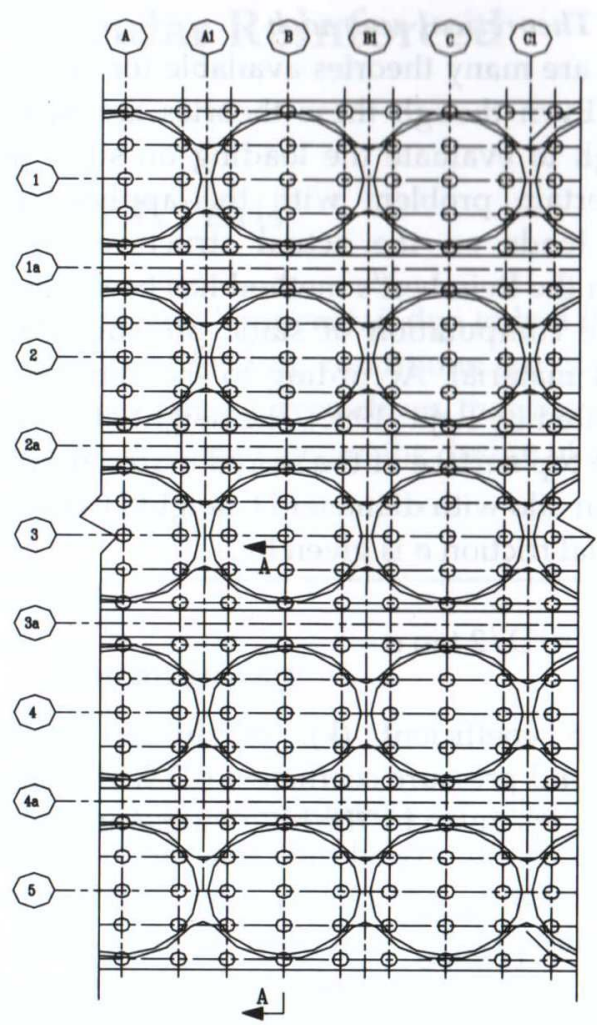

Figure 1: Pile layout

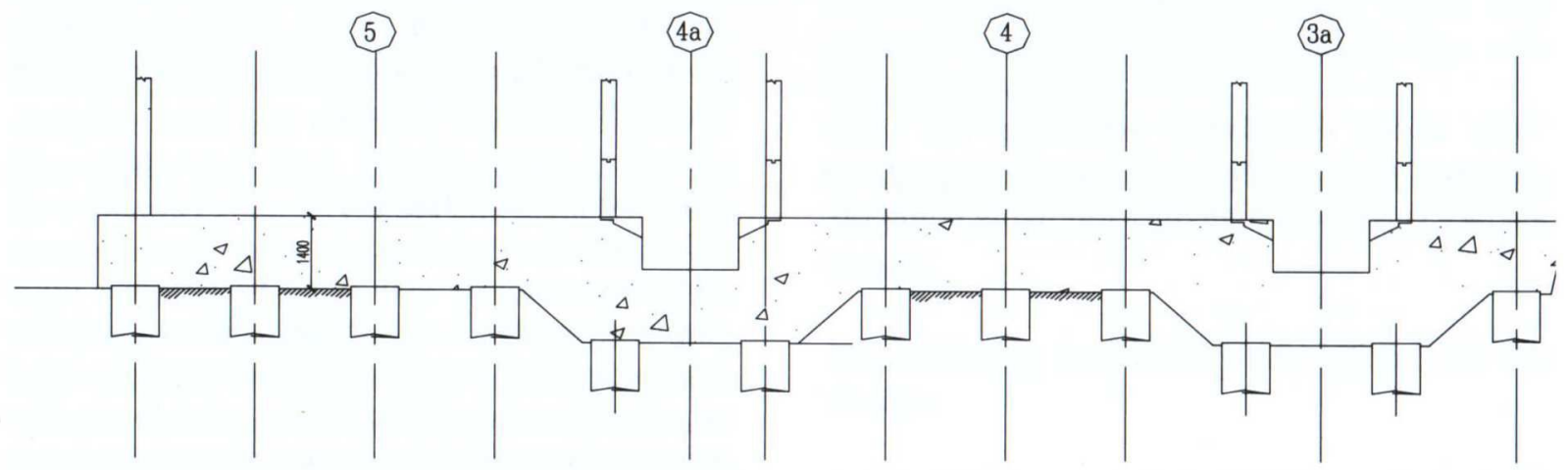

Figure 2: Section of Piled Raft foundation

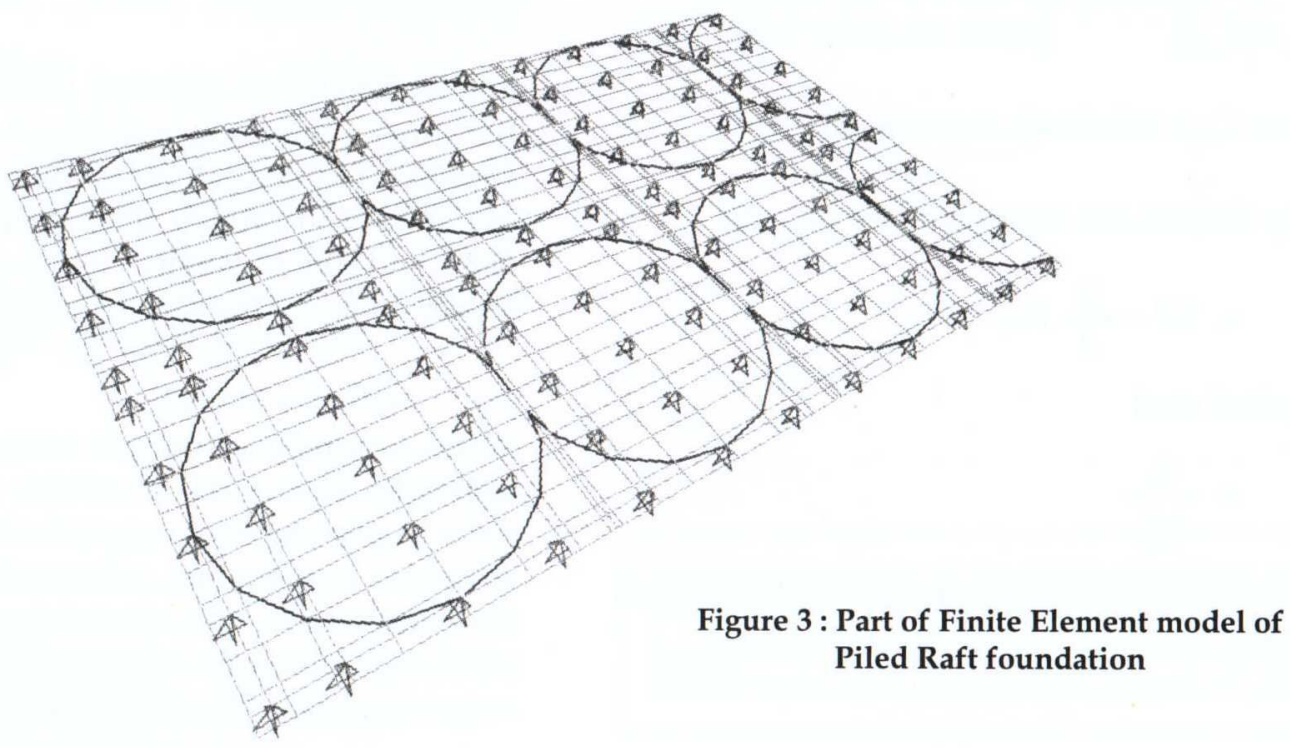




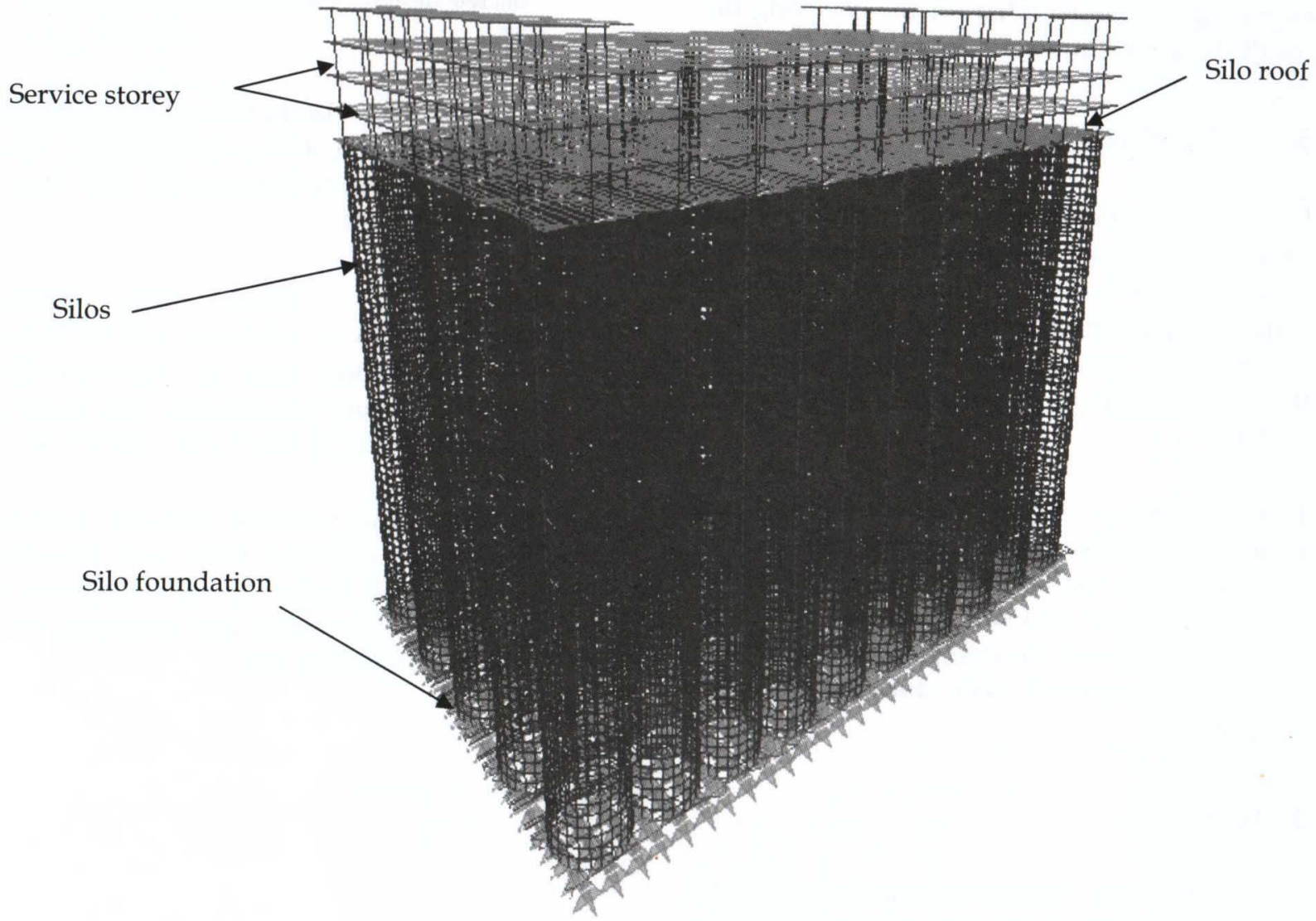

Figure 4: Complete Model- Silos, Foundation and Top structure

\section{Results and Discussion}

4.1 Deflection and fundamental period of vibration.

\begin{tabular}{|l|c|}
\hline \multicolumn{1}{|c|}{ Parameter } & \multicolumn{1}{c|}{ Value } \\
\hline $\begin{array}{l}\text { Fundamental period } \\
\text { of vibration }\end{array}$ & $1.0 \mathrm{sec}$ \\
\hline $\begin{array}{l}\text { Maximum deflection } \\
\text { for wind load }\end{array}$ & $8.00 \mathrm{~mm}$ \\
\hline
\end{tabular}

Table1: Results for lateral stability

It can be seen from these results that deflection $8.00 \mathrm{~mm}$ and a natural period of vibration is 1.0 second are within the acceptable limit. According to the rule of thumb period tallies with a 10 story building. Even though the total height of the structure is about $62.0 \mathrm{~m}$, the calculated fundamental period of vibration is less, it can be stated that the silo structure could be more rigid than a building of same height.

\begin{tabular}{|l|c|c|}
\hline \multicolumn{1}{|c|}{ Parameter } & $\begin{array}{c}\text { Numerical } \\
\text { (Modeling) }\end{array}$ & Manual \\
\hline $\begin{array}{l}\text { Maximum Hoop } \\
\text { tension force in silo } \\
\text { wall }\end{array}$ & $385.47 \mathrm{kN}$ & $355.01 \mathrm{kN}$ \\
\hline $\begin{array}{l}\text { Maximum Vertical } \\
\text { force in silo wall }\end{array}$ & $1830.18 \mathrm{kN}$ & $1672.48 \mathrm{kN}$ \\
\hline
\end{tabular}

Table 2: Analysis results of forces

The results shown above is at the base level of the silo wall and considering the given load combinations. It is clear that numerical model results are slightly higher than manual calculated results. The difference between numerical and manual calculation is about $9 \%$. This may not be a very significant value since the partial factors of safety for material strength and loading can easily accommodate such variations resulting from different method of analysis. However, the use of finite element method of modeling with shell elements will allow significant, improvement in presentation and also less reliance on empirical methods. Nevertheless, 
the continues use of manual methods can still be strongly recommended for the checking the results from the finite element models.

\section{Conclusion}

It can be concluded that with a proper finite element model will yield the required design parameters for the silos. All loading combination could be applied correctly and accurately as a complete 3D model could be analyzed rather than analyzing parts by parts as done in manual method.

The final answer of finite element method and manual methods are of comparable nature. However, the use of finite element method with both supper and sub structures would be possible and hence the designer will be able to have greater control over studying different scenarios.

\section{References}

1. Allen, A.H., "Reinforced concrete design to BS 8110," Spons Architecture, India, pp 193-202.

2. British Standards, BS 6399 - Part I, (1984), "Design loading for building".

3. British Standards, BS 8110 - Part I and Part II, (1985), "Structural use of concrete".

4. CP3 : Chapter V : Part 2, (1972), "Code of basic data for the design of buildings - wind loading".

5. Dias, W.P.S. (1995), "Graded examples in reinforced concrete design," Society of structural engineers, Sri Lanka, pp 90-107.

6. Ministry of housing and construction, (1980), "Design of buildings for high wind Sri Lank," July, pp 18-40.

7. Mosley, W.H., Bungey, J.H. "Reinforced concrete design," Macmillan press Ltd, pp 192-230.

8. Poukhonto, L.M. (2003), “Durability of Concrete Structures and Constructions: Silos, Bunkers, Reservoirs, Water Towers, Retaining Walls," Routledge publisher, New Zealand, pp 424-500.
9. Raju, N.K. (1996) "Advanced reinforced concrete design," CBS Publishers, India, pp 82 137.

10. Safarian, S.S., Harris, E.C. (1985), "Design and Construction of Silos and Bunkers," Van Nostrand Reinhold Company Ed, New York, USA, pp 90 - 104.

11. Safarian, S.S., Harris, E.C. (1970), "Determination of minimum wall thickness and temperature steel in conventionally reinforced circular concrete silos," ACI journal, Proceeding, Vol.67, No. 7, July, pp 539-547.

12. SAP2000, "Basic Analysis reference manual, linear and nonlinear static and dynamic analysis and design of three-dimensional structures," Computers and Structures, Inc, Berkeley, California, USA. 